\title{
Microsatellite Instability Analysis and Its Prognostic Value in Invasive Nonampullary Duodenal Adenocarcinoma
}

\section{Guang Yang}

Okayama University: Okayama Daigaku

Takehiro Tanaka ( $\nabla$ takehiro@md.okayama-u.ac.jp)

Okayama University https://orcid.org/0000-0002-1509-5706

\section{Hideaki Kinugasa}

Okayama University Graduate School of Medicine Dentistry and Pharmaceutical Sciences: Okayama Daigaku Daigakuin Ishiyakugaku Sogo Kenkyuka Igakubu

Hiromitsu Kanzaki

Okayama University Graduate School of Medicine Dentistry and Pharmaceutical Sciences: Okayama Daigaku Daigakuin Ishiyakugaku Sogo Kenkyuka Igakubu

\section{Xi Meng Chen}

Okayama University Graduate School of Medicine Dentistry and Pharmaceutical Sciences: Okayama Daigaku Daigakuin Ishiyakugaku Sogo Kenkyuka Igakubu

\section{Koichi Ichimura}

Hiroshima City Hospital

\section{Masahiro Nakagawa}

Hiroshima citizen hospital

\section{Shun Zai Jin}

Mudanjiang Medical University

\section{Yi Ru Zheng}

The Mine Hospital of Xu Zhou

\section{Tadashi Yoshino}

Okayama University Graduate School of Medicine Dentistry and Pharmaceutical Sciences: Okayama Daigaku Daigakuin Ishiyakugaku Sogo Kenkyuka Igakubu

\section{Research Article}

Keywords: PD-L1 expression, invasive nonampullary duodenal adenocarcinoma, microsatellite instability, prognosis, immunotherapy

Posted Date: August 11th, 2021

DOI: https://doi.org/10.21203/rs.3.rs-784037/v1

License: (9) (1) This work is licensed under a Creative Commons Attribution 4.0 International License. Read Full License

Version of Record: A version of this preprint was published at Oncology on March 29th, 2022. See the published version at https://doi.org/10.1159/000519805. 


\section{Abstract}

Purpose: Nonampullary duodenal adenocarcinoma is a rare disease. Although several prognostic factors have been reported for this disease, they remain controversial due to their rarity. In this study, we retrospectively analyzed 54 cases of invasive nonampullary duodenal adenocarcinoma, focusing on the microsatellite instability phenotype, PD-L1 expression, and prognostic factors.

Methods: Expression of the PD-L1 protein and cell differentiation markers in tumors was detected by immunohistochemistry. Microsatellite markers (NR-21, NR-22, NR-24, BAT-25 and BAT-26) were amplified for MSI assessment by PCR.

Results: The incidence of microsatellite instability in invasive nonampullary duodenal adenocarcinoma was $35.2 \%$. No significant correlation between the microsatellite instability phenotype and clinicopathological factors was observed. Positive expression of PD-L1 by immune cells was common in advanced-stage disease $(P=0.054)$, and positive expression of PD-L1 in cancer cells correlated significantly with the histologically undifferentiated type $(P=0.016)$. Kaplan-Meier survival analysis demonstrated a significantly better overall survival in patients with microsatellite instability $(P=0.013)$ and at early-stage disease $(P=0.000)$ than in those with microsatellite stability or at late tumor stages. Univariate and multivariate analyses showed that microsatellite instability


$8.81,95 \%$ confidence interval [Cl]: $2.545-30.500, p=0.001$ ) were independent better prognostic factors of overall survival.

Conclusions: Microsatellite instability and early tumor stage (stage $\mathbb{\bigotimes} \rrbracket$ ) were independent better prognostic factors of overall survival. A high proportion of microsatellite instability phenotypes and positive PD-L1 expression may be helpful for identifying immune checkpoint inhibitors as a novel therapeutic strategy.

\section{Introduction}

Small bowel adenocarcinoma (SBA) is rare compared with other gastrointestinal cancers, and primary small bowel malignancies are even rarer, accounting for less than $5 \%$ of all gastrointestinal tumors (Zheng et al. 2021). The duodenum is the most proximal part of the small intestine and has some distinctive tissue characteristics due to its direct continuity with the pylorus (Yoshida et al. 2019). The incidence rate of duodenal carcinoma is very rare, accounting for only approximately $0.3 \%$ of all gastrointestinal cancers and for $30-50 \%$ of all SBAs. Nevertheless, its morbidity is increasing worldwide (Takinami et al. 2020; Xue et al. 2017). To better elucidate the clinicopathological, histological and immune-phenotypic characteristics of duodenal tumors, a more powerful position-specific classification strategy has been established. Many tumors that were once considered to be duodenal tumors have been shown to be composed of unique and specific subtypes, such as some tumors originating from the vater ampulla, tumors mainly growing in the ampullary duodenal surface, and those that arise from the nonampullary duodenum (Xue et al. 2017).

Nonampullary duodenal adenocarcinoma (NADA) is a type of small intestinal adenocarcinoma that can be classified into two types according to immunophenotypic characteristics: intestinal and gastric phenotypes. Gastric-type carcinomas are more frequently located on the oral side of the vater-ampulla (oral vater) and tend to show high malignant potential, whereas intestinaltype tumors tend to be located on the anal side of the vater-ampulla (anal vater) and have lower malignant potential than gastrictype tumors (Matsueda et al. 2019; Ota et al. 2020). Some reports have described TNM stage, tumor size and location as prognostic factors, but these factors are still controversial due to the rarity of NADA (Hirashita et al. 2018; Kato et al. 2014; Ryder et al. 2000; Zenali et al. 2013).

Microsatellites are also known as simple sequence repeats (SSRs) or short tandem repeats (STRs), with repeat units composed of 1-6 nucleotide DNA motifs (Srivastava et al. 2019). Microsatellites are widely distributed in the genome and are closely related to many important genes (Cullis 2002). Moreover, their distribution is not random in many eukaryotes. Indeed, microsatellites are more likely to be located in the noncoding than in the coding region of the genome. Mutations or epigenetic changes in DNA mismatch repair (MMR) genes destroy the normal function of the DNA MMR system, and the number of allelic microsatellite base pairs will change, which is termed microsatellite instability (MSI) (Yang et al. 2019). In many malignant tumors, MSI detection is considered to be an effective predictor for evaluating prognosis and response to chemotherapy. In gastric and colorectal cancer (CRC), patients with MSI have a more favorable prognosis than those with a microsatellite-stable (MSS) status. Additionally, a significant correlation between MSI and programmed cell death-ligand 1 (PD-L1) expression has been reported, and the MSI phenotype is used 
as a predictor for response to immunotherapy. Based on anti-PD-1/PD-L1 antibody immune checkpoint inhibitors, microsatellite instability-high (MSI-H) patients benefit significantly from immunotherapy compared with MSS and microsatellite instability-low (MSI-L) patients (Lin et al. 2020; Liu et al. 2020). Therefore, detection of biomarkers, including MSI and expression of PD-L1, is necessary to screen patients who should exhibit strong responses to immunotherapy. Nevertheless, there are to date relatively few relevant studies for duodenal cancer, and the prognostic value of the MSI phenotype is also controversial (Aparicio et al. 2013; Overman et al. 2010; Watari et al. 2019).

The present study entailed subsequent investigation of the microsatellite status and expression of PD-L1 as well as correlation among clinicopathological factors, immunophenotype (PD-L1 expression) and microsatellite status in invasive nonampullary duodenal adenocarcinoma (INADA). We also sought to evaluate prognostic factors for overall survival (OS).

\section{Material And Methods}

\section{Patients}

This research was carried out according to the institutional review board (IRB) requirements of Okayama University Affiliated Hospital (No. 2103-051) and Hiroshima City Hospital (No. 2021-8). Fifty-four INADA patients who were treated in Okayama University Affiliated Hospital or Hiroshima City Hospital from 2006 to 2018 were enrolled in this study. Formalin-fixed paraffinembedded (FFPE) tissue blocks from patients who had undergone biopsy or resection by endoscopy or surgery for stage $\mathbb{X}-\mathbb{Q}$ INADA were obtained. Informed consent was obtained by the opt-out method.

\section{Clinicopathological evaluation}

Medical records of patients were reviewed, and the following clinicopathological parameters were collected: sex, age, tumor location, histological differentiation, and tumor TNM stage. All INADA patients were staged according to the combined American Joint Committee on Cancer/Union for International Cancer Control (AJCC/UICC) TNM staging system (Brierley JD et al. 2017). We defined carcinoma that infiltrated into the submucosa (T1) and deeper tissue (T2, T3 and T4) as invasive cancer. Based on previous relevant reports (Benson et al. 2019; Sakae et al. 2017; Watari et al. 2019), stage III or IV SBA has significantly worse outcomes than earlier-stage disease. Therefore, tumors without lymph node invasion (N0) and distant metastasis (M0) were tentatively classified as early-stage tumors (stage $\mathbb{\varangle}-\mathbb{Z}$ ); tumors with lymph node invasion (N1/2) or distant metastasis (M1) were

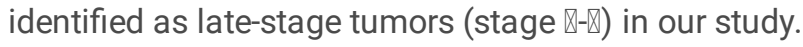

\section{Immunohistochemistry}

Expression of the PD-L1 protein and cell differentiation markers in tumors from 54 patients with INADA was detected by immunohistochemistry (IHC). FFPE tissue sections with a thickness of $4 \mu \mathrm{m}$ were prepared and subjected to $\mathrm{IHC}$ with an automated Bond-III slide stainer (Leica Biosystems, Wetzlar, Germany) in accordance with the manufacturer's protocol using mouse anti-human monoclonal antibodies against MUC6 (clone CLH5; 1:100; Novus, America), MUC5AC (clone CLH2; 1:100; DAKO, Denmark), MUC2 (clone CCP58; 1:100; DAKO, Denmark), CD10 (clone 56C6; 1:70; Leica, Germany), and PD-L1 (clone SP263; rabbit monoclonal primary anti-PD-L1 antibody, prediluted, Ventana Medical Systems, Tucson, AZ). For PD-L1, reactivity was evaluated separately for cancer cells and infiltrating immune cells. Cases with $\geq 1 \%$ of cells (membrane staining) being stained were considered to be PD-L1 positive (Pollack et al. 2021). For mucin histochemical staining, cytoplasmic reactivity was determined to be a positive outcome for MUC6, MUC5AC and MUC2, and luminal membranous reactivity was determined to be a positive result for CD10. Gastric phenotypic markers (MUC6 and MUC5AC) and intestinal phenotypic markers (MUC2 and CD10) were evaluated as positive when immunoreactivity was observed in $\geq 10 \%$ of tumor cells (Yoshida et al. 2019). INADA was classified into 4 subtypes based on mucin histochemistry: 1. Gastric type (G-type); 2. Intestinal type (I-type); 3. Mixed type (including G and I type) and 4. Null phenotype. IHC results were evaluated by 2 experienced pathologists.

\section{DNA extraction}

DNA from tumor and normal tissue was extracted in accordance with manufacturer's instructions. In short, for lysis, we digested tumor and matched normal tissues at $56^{\circ} \mathrm{C}$ overnight using Qiagen DNA Extraction Kit. The tissues were then incubated at $90^{\circ} \mathrm{C}$ for 1 hour to inactivate proteinase K, and the released DNA was adsorbed onto silica membranes in QIAamp mini spin columns 
(Qiagen). After extensive washing with AW1/AW2 buffers, the DNA was dissolved in AE buffer, and the concentration was determined by using a NanoDrop spectrophotometer.

\section{MSI detection}

The fluorescently labeled primers and automated DNA sequencing techniques used have been described previously (Oda et al. 1997). In brief, five quasi-monomorphic mononucleotide markers (NR-21, NR-22, NR-24, BAT-25 and BAT-26) were amplified for MSI assessment by PCR. The forward primer for each biomarker was labeled with a fluorescent dye, such as 6-carboxyfluorescein (6FAM) or 6-carboxy-2',4,4',5',7,7'-hexachlorofluororescein (HEX) or 5-carboxy-tetramethylrhod-amine (TAMRA). PCR conditions for the assay consisted of an initial 10 -min denaturation step at $95^{\circ} \mathrm{C}$, followed by 40 cycles at $95^{\circ} \mathrm{C}$ for $30 \mathrm{~s}, 55^{\circ} \mathrm{C}$ for $30 \mathrm{~s}$, and $72^{\circ} \mathrm{C}$ for $1 \mathrm{~min}$, with a final extension at $72^{\circ} \mathrm{C}$ for $10 \mathrm{~min}$. The forward and reverse sequences of each primer, corresponding annealing temperature and PCR product size are listed in Table 1. To determine whether microsatellite shifts were present in tumor tissues, we mixed the fluorescence-labeled PCR products of these five microsatellite markers and performed coelectrophoretic sequencing of the mixture using an $\mathrm{ABI} 310$ gene sequencer. Finally, we used peak scanner software version 1.0 to analyze the sequencing data and compared it with normal tissues.

In 1997, the American National Cancer Institute ( $\mathrm{NCl}$ ) proposed that MSI was defined if $\geq 1$ microsatellite locus was shifted among five microsatellite markers. When no microsatellite marker shift was observed, it is called MSS (Boland et al. 1998).

\section{Statistical analysis}

All categorical variables between two groups were compared by Pearson's chi-square test or Fisher's exact test, as appropriate, and the results are presented as numbers and percentages. All continuous variables between groups were compared by Student's $t$ test, and the results are reported as medians (ranges). OS was evaluated by the Kaplan-Meier method. Differences between groups were assessed by the log-rank test. The Cox proportional hazards regression model was used to evaluate the multicovariate predictive impact on OS. Statistical significance was defined as $\mathrm{P}<0.05$ with a two-tailed test. All statistical analyses were performed using SPSS statistical software version 24.0.

\section{Result}

\section{Clinicopathological characteristics of INADA}

The clinicopathological characteristics of the 54 patients with INADA are summarized in Table 2. The median age of the patients was 68 years (range: $29-90$ years), with a male dominance (male/female ratio of 2.0$)$. Forty $(74.1 \%)$ and fourteen $(25.9 \%)$ tumors were located in the oral vater and anal vater, respectively. Histologically, differentiated adenocarcinoma was more common

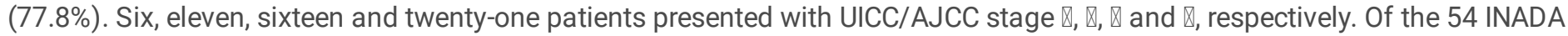
cases, G-type was the most common and was identified in 33 patients (61.1\%). I-type, mixed and null mucin types were observed in 7,6 and 8 cases, respectively. For PD-L1, we evaluated expression in cancer cells and immune cells in the stroma, and positive expression rates were $44.4 \%(24 / 54)$ and 59.3\% (32/54), respectively. The MSI phenotype, including MSI-L and MSI-H, was found in 19/54 patients (35.2\%).

\section{Differentiated type versus undifferentiated type}

Relevant clinicopathological factors are shown in Table 3. Histologically, undifferentiated adenocarcinoma was more frequently identified as a G-type and the null phenotype $(P=0.037)$. Undifferentiated adenocarcinoma was also more frequently observed in the later stage $(\mathbb{Q})(P=0.023)$. At the same time, the undifferentiated type correlated significantly with expression of PD-L1 in tumor cells $(P=0.016)$ and immune cells $(P=0.094)$, though no statistical significance was found for immune cells. In addition, no statistical significance was observed between other clinicopathological factors and histological type.

\section{PD-L1+ versus PD-L1-}

According to our evaluation criteria for PD-L1 expression, cases with $\geq 1 \%$ cell membrane staining were defined as positive. The correlation between PD-L1 expression and clinicopathological factors is described in Table 3. Simultaneous PD-L1 expression in 
tumor and stromal immune cells was detected for 19 patients (35.2\%). Representative images of PD-L1 expression are provided in Fig. 1. In stromal immune cells, positive expression of PD-L1 correlated significantly with advanced tumor stage $(P=0.054)$. However, there was no correlation for other clinicopathological factors, such as tumor location, tumor type, mucin phenotype and PD-L1 expression in immune cells. In tumor cells, only an association between PD-L1 expression and the undifferentiated type was identified $(P=0.016)$, with no correlation for any of the other clinicopathological factors. Of all 19 cases with MSI, 14 were positive for PD-L1 expression in tumors or in immune cells, but no significant correlation between MSI and PD-L1 expression was observed.

\section{MSS versus MSI}

Among all 54 INADA cases, 19 exhibited the MSI phenotype. A representative MSI image is shown in Fig. 2. Compared with normal tissue, MSI markers NR-21, NR-24, BAT-25 and BAT-26 displayed significant translocation in tumor tissues. The correlation between microsatellite status and clinicopathological factors is provided in Table 4. Although statistical significance was not reached for all, MSI cases tended to involve anal vater compared with MSS cases $(P=0.058)$.

\section{Impact of microsatellite status, PD-L1 expression, tumor stage, and tumor type and location on patient survival}

The prognostic value of microsatellite status, PD-L1 expression, and tumor stage, type and location for patient survival was assessed by Kaplan-Meier curve analysis, which demonstrated that INADA with MSI $(P=0.013)$ and earlier stage $(P=0.000)$ were associated with better OS by the log-rank test (Fig. 3). However, PD-L1 expression and tumor type and location had no relevant influence on patient OS (Fig. 4). Furthermore, univariate and multivariate analyses revealed that MSI (hazard ratio [HR]: 0.282, 95\%

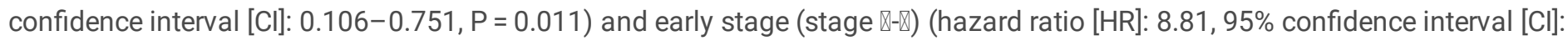
2.545-30.500, $P=0.001$ ) were independently related to better OS, as shown in Table 5.

\section{Discussion}

In this study, we detected the microsatellite phenotype, mucin phenotype and PD-L1 expression of INADA by PCR and IHC. Among 54 patients, 19 showed the MSI phenotype (35.2\%), which is lower than the rate of $51.6 \%$ reported by Watari et al. (Watari et al. 2019). This discrepancy may be attributed to different microsatellite markers used, different detection methods, or patients with different malignancies. In our study, all patients were classified as having INADA, which invaded the submucosa (T1) and deeper tissues (T2, T3 and T4), whereas the study reported by Watari et al included all stages of NADA from stage 0 to stage IV. Nonetheless, the MSI rate reported by us was similar to other reported rates in small bowel cancer (Overman et al. 2010; Warth et al. 2011). According to our analysis, there was no significant correlation between microsatellite status and clinicopathological factors. In general, immune checkpoint ligands, including PD-L1, are strongly expressed in the MSI tumor microenvironment to counterbalance the antitumor immune activity of cytotoxic T lymphocytes. Several studies have reported a correlation between MSI and PD-L1 expression in gastrointestinal tumors, some of which showed that the MSI phenotype correlates positively with PD-L1 expression (Choi et al. 2020; Giuffrida et al. 2020; Liu et al. 2020). The lack of a positive correlation between MSI and PD-L1 expression in tumor/immune cells in our study is consistent with some recent reports (Klose et al. 2020; Salem et al. 2018; Watari et al. 2019). In general, expression of PD-L1 in tumor cells is variable and not always accompanied by MSI. PD-L1 expression may also be affected by other factors, such as the tumor mutational burden and number of CD8 + tumor-infiltrating lymphocytes. MSIL/low tumor mutational burden but high PD-L1 positive expression have been observed in gastrointestinal stromal tumors, anal cancer and esophageal squamous cell carcinoma (Salem et al. 2018).

Through Kaplan-Meier survival analysis, we found that INADA patients with MSI had better survival than did patients with MSS (P $=0.013$ ), which was consistent with the results of previous studies in gastric cancer, small bowel cancer and CRC (Giuffrida et al. 2020; Polom et al. 2018; Yang et al. 2019; Yang et al. 2020). The detailed mechanism by which MSI-positive patients have a better prognosis has been explored, and it appears that this phenomenon may be due to a strong antitumor immune response triggered in the tumor microenvironment. MSI patients tend to present a higher tumor mutational burden and strong ability to produce novel, nonself neoantigens, such that many more cytotoxic T lymphocytes are attracted to infiltrate into the tumor microenvironment. These high-density tumor-infiltrating lymphocytes inhibit the invasion and infiltration of cancer cells. Therefore, MSI patients often have a favorable prognosis and good survival time (Badalamenti et al. 2019). Because MSI patients have a higher tumor mutational burden, $\mathrm{MSI}$ in coding regions predisposes generation of truncated proteins as novel antigens, also known as frameshift peptides (FSPs), as a result of frameshift mutations. Extensive studies related to FSP vaccines have been conducted 
(Roudko et al. 2020). For example, through basic research, Leoni $\mathrm{G}$ et al (Leoni et al. 2020) found that the FSP vaccine can induce the optimal extent of the immune response, which might result in clinical benefits for preventing and treating MSI tumors.

Therefore, we speculate that combination therapy of the FSP vaccine and immune checkpoint inhibitors based on anti-PD-1/PD-L1 antibodies may be able to achieve greater benefits than the single use of immune checkpoint inhibitors for MSI/PD-L1 + tumor patients.

Tumor stage is the most important prognostic factor in SBA (Zaaimi et al. 2016), and we found that the survival of patients gradually worsened with increasing tumor stage. It is well known that advanced cancer patients have a worse prognosis, as reported by many studies (Aparicio et al. 2013; Huffman et al. 2019; Ocasio Quinones and Woolf 2021; Raghav and Overman 2013; Zaaimi et al. 2016).

Many previous studies have been carried out to evaluate the prognostic value of PD-L1 expression in tumor cells and immune cells in different cancers (Fu et al. 2020; Giuffrida et al. 2020; Klose et al. 2020; Liu et al. 2020; Morihiro et al. 2019; Zhou et al. 2020), though the association between PD-L1 expression and prognosis is controversial. Klose et al (Klose et al. 2020), Giuffrida et al (Giuffrida et al. 2020), and Liu et al (Liu et al. 2020) reported that patients with PD-L1-positive expression have better survival outcomes than PD-L1-negative patients. At the same time, PD-L1 positive expression has been related to worse OS, as reported by Morihiro et al (Morihiro et al. 2019), Zhou et al (Zhou et al. 2020), Dai et al (Dai et al. 2018), and Fu et al (Fu et al. 2020). In our current study, no significant correlation was observed between PD-L1 expression and OS, which is consistent with a recent report (Bonanno et al. 2018). This discrepancy may be due to the different therapeutic methods provided to patients, such as chemotherapy and immunotherapy. For those with positive expression of PD-L1, immune checkpoint inhibitors, such as antibodies against PD-1/PD-L1, may improve survival.

Our research has some limitations. First, NADA is a rare disease, and the sample size included in this study was quite small. Second, due to the lack of sufficient tissue, we were unable to detect the density of tumor-infiltrating lymphocytes by IHC. Recently, it has been reported that PD-L1 expression with MSI/CD8 + lymphocyte infiltration is considered an important and useful indicator to predict the effectiveness of immune checkpoint inhibitors (Noh et al. 2020).

In conclusion, the MSI phenotype and an early tumor stage were significantly associated with better survival than MSS and a late tumor stage, and both were independent better prognostic factors. However, there was no significant correlation between the MSI phenotype and PD-L1 expression. Moreover, expression of PD-L1 in tumor cells/immune cells was not related to prognosis. A high proportion of MSI phenotypes and PD-L1 expression may be helpful when considering immune checkpoint inhibitors as a therapeutic strategy. In addition, a comprehensive assessment of predictors of immune checkpoint inhibitors, including the tumor mutational burden, density of tumor-infiltrating lymphocytes and expression of PD-1 and other molecular checkpoints, is needed in addition to PD-L1 expression and microsatellite status evaluations.

\section{Declarations}

\section{Funding}

Not applicable.

\section{Conflicts of interest/Competing interests}

The authors declare that they have no known competing financial interests or personal relationships that could have appeared to influence the work reported in this paper.

\section{Availability of data and material}

All data generated or analyzed during this study are included in this published article.

\section{Code availability}

Not applicable. 
This study was designed by Takehiro Tanaka, Hideaki Kinugasa and Hiromitsu Kanzaki. Guang Yang and Ru-yi Zheng contributed to the data collection and analysis. The manuscript was written by Guang Yang, Masahiro Nakagawa and Meng-xi Chen.

Pathological evaluation was performed by Takehiro Tanaka and Koichi Ichimura. Tadashi Yoshino and Zai-shun Jin contributed to revise of manuscript and commented on by all authors.

\section{Ethics approval}

This study was approved by Okayama University Affiliated Hospital (IRB: 2103-051) and Hiroshima City Hospital (IRB: 2021-8).

\section{Consent to participate}

Informed consent was obtained by the opt-out method.

\section{Consent for publication}

All the authors listed have approved the publication of manuscript in Journal of Cancer Research and Clinical Oncology.

\section{Acknowledgements}

Yuri Tamada and Mutsumi Okabe provided experimentally technical support.

\section{References}

1. Aparicio T et al. (2013) Small bowel adenocarcinoma phenotyping, a clinicobiological prognostic study British journal of cancer 109:3057-3066 doi:10.1038/bjc.2013.677

2. Badalamenti $\mathrm{G}$ et al. (2019) Role of tumor-infiltrating lymphocytes in patients with solid tumors: Can a drop dig a stone? Cellular immunology 343:103753 doi:10.1016/j.cellimm.2018.01.013

3. Benson AB et al. (2019) Small Bowel Adenocarcinoma, Version 1.2020, NCCN Clinical Practice Guidelines in Oncology Journal of the National Comprehensive Cancer Network : JNCCN 17:1109-1133 doi:10.6004/jnccn.2019.0043

4. Boland CR et al. (1998) A National Cancer Institute Workshop on Microsatellite Instability for cancer detection and familial predisposition: development of international criteria for the determination of microsatellite instability in colorectal cancer Cancer research 58:5248-5257

5. Bonanno L et al. (2018) The role of immune microenvironment in small-cell lung cancer: Distribution of PD-L1 expression and prognostic role of FOXP3-positive tumour infiltrating lymphocytes European journal of cancer (Oxford, England : 1990) 101:191-200 doi:10.1016/j.ejca.2018.06.023

6. Brierley JD et al. (2017) TNM Classification of Malignant tumours. 8th edn.

7. Choi E et al. (2020) Prognostic perspectives of PD-L1 combined with tumor-infiltrating lymphocytes, Epstein-Barr virus, and microsatellite instability in gastric carcinomas Diagnostic pathology 15:69 doi:10.1186/s13000-020-00979-z

8. Cullis CA (2002) The use of DNA polymorphisms in genetic mapping Genetic engineering 24:179-189 doi:10.1007/978-1-46150721-5_8

9. Dai X, Pi G, Yang SL, Chen GG, Liu LP, Dong HH (2018) Association of PD-L1 and HIF-1a Coexpression with Poor Prognosis in Hepatocellular Carcinoma Translational oncology 11:559-566 doi:10.1016/j.tranon.2018.02.014

10. Fu X et al. (2020) PD-L1 Predicts Poor Prognosis in Surgically Resected Limited Stage Small-Cell Lung Cancer Cancer management and research 12:10939-10948 doi:10.2147/cmar.S260599

11. Giuffrida P et al. (2020) PD-L1 in small bowel adenocarcinoma is associated with etiology and tumor-infiltrating lymphocytes, in addition to microsatellite instability Modern pathology : an official journal of the United States and Canadian Academy of Pathology, Inc 33:1398-1409 doi:10.1038/s41379-020-0497-0

12. Hirashita T et al. (2018) Prognostic factors of non-ampullary duodenal adenocarcinoma Japanese journal of clinical oncology 48:743-747 doi:10.1093/jjco/hyy086 
13. Huffman BM et al. (2019) Novel Prognostic Factors in Resected Small Bowel Adenocarcinoma Clinical colorectal cancer 18:218-225 doi:10.1016/j.clcc.2019.05.002

14. Kato Y, Takahashi S, Kinoshita T, Shibasaki H, Gotohda N, Konishi M (2014) Surgical procedure depending on the depth of tumor invasion in duodenal cancer Japanese journal of clinical oncology 44:224-231 doi:10.1093/jjco/hyt213

15. Klose $\mathrm{J}$ et al. (2020) Prognostic relevance of programmed death-ligand 1 expression and microsatellite status in small bowel adenocarcinoma Scandinavian journal of gastroenterology 55:321-329 doi:10.1080/00365521.2020.1734073

16. Leoni G et al. (2020) A Genetic Vaccine Encoding Shared Cancer Neoantigens to Treat Tumors with Microsatellite Instability Cancer research 80:3972-3982 doi:10.1158/0008-5472.Can-20-1072

17. Lin A, Zhang J, Luo P (2020) Crosstalk Between the MSI Status and Tumor Microenvironment in Colorectal Cancer Frontiers in immunology 11:2039 doi:10.3389/fimmu.2020.02039

18. Liu X et al. (2020) High PD-L1 expression in gastric cancer (GC) patients and correlation with molecular features Pathology, research and practice 216:152881 doi:10.1016/j.prp.2020.152881

19. Matsueda K et al. (2019) The clinicopathological differences of sporadic non-ampullary duodenal epithelial neoplasm depending on tumor location Journal of gastroenterology and hepatology 34:1540-1544 doi:10.1111/jgh.14640

20. Morihiro T et al. (2019) PD-L1 expression combined with microsatellite instability/CD8+ tumor infiltrating lymphocytes as a useful prognostic biomarker in gastric cancer Scientific reports 9:4633 doi:10.1038/s41598-019-41177-2

21. Noh BJ, Hong SM, Jun SY, Eom DW (2020) Prognostic implications of immune classification in a multicentre cohort of patients with small intestinal adenocarcinoma Pathology 52:228-235 doi:10.1016/j.pathol.2019.09.004

22. Ocasio Quinones GA, Woolf A (2021) Small Bowel Cancer. In: StatPearls. StatPearls Publishing Copyright (C) 2021, StatPearls Publishing LLC., Treasure Island (FL),

23. Oda S, Oki E, Maehara Y, Sugimachi K (1997) Precise assessment of microsatellite instability using high resolution fluorescent microsatellite analysis Nucleic acids research 25:3415-3420 doi:10.1093/nar/25.17.3415

24. Ota R et al. (2020) Integrated genetic and epigenetic analysis of cancer-related genes in non-ampullary duodenal adenomas and intramucosal adenocarcinomas The Journal of pathology 252:330-342 doi:10.1002/path.5529

25. Overman MJ, Pozadzides J, Kopetz S, Wen S, Abbruzzese JL, Wolff RA, Wang H (2010) Immunophenotype and molecular characterisation of adenocarcinoma of the small intestine British journal of cancer 102:144-150 doi:10.1038/sj.bjc.6605449

26. Pollack R, Kagan M, Dresner-Pollak R, Neuman T (2021) PD-L1 EXPRESSION IN NORMAL ENDOCRINE TISSUES IS NOT INCREASED DESPITE HIGH INCIDENCE OF PD-1 INHIBITOR-ASSOCIATED ENDOCRINOPATHIES Endocrine practice : official journal of the American College of Endocrinology and the American Association of Clinical Endocrinologists 27:34-37 doi:10.1016/j.eprac.2020.11.004

27. Polom K et al. (2018) Meta-analysis of microsatellite instability in relation to clinicopathological characteristics and overall survival in gastric cancer The British journal of surgery 105:159-167 doi:10.1002/bjs.10663

28. Raghav K, Overman MJ (2013) Small bowel adenocarcinomas-existing evidence and evolving paradigms Nature reviews Clinical oncology 10:534-544 doi:10.1038/nrclinonc.2013.132

29. Roudko V et al. (2020) Shared Immunogenic Poly-Epitope Frameshift Mutations in Microsatellite Unstable Tumors Cell 183:1634-1649.e1617 doi:10.1016/j.cell.2020.11.004

30. Ryder NM, Ko CY, Hines OJ, Gloor B, Reber HA (2000) Primary duodenal adenocarcinoma: a 40-year experience Archives of surgery (Chicago, III : 1960) 135:1070-1074; discussion 1074-1075 doi:10.1001/archsurg.135.9.1070

31. Sakae $\mathrm{H}$ et al. (2017) The characteristics and outcomes of small bowel adenocarcinoma: a multicentre retrospective observational study British journal of cancer 117:1607-1613 doi:10.1038/bjc.2017.338

32. Salem ME et al. (2018) Landscape of Tumor Mutation Load, Mismatch Repair Deficiency, and PD-L1 Expression in a Large Patient Cohort of Gastrointestinal Cancers Molecular cancer research : MCR 16:805-812 doi:10.1158/1541-7786.Mcr-17-0735

33. Srivastava S, Avvaru AK, Sowpati DT, Mishra RK (2019) Patterns of microsatellite distribution across eukaryotic genomes BMC genomics 20:153 doi:10.1186/s12864-019-5516-5

34. Takinami M et al. (2020) Endoscopic features of submucosal invasive non-ampullary duodenal carcinomas Journal of gastroenterology and hepatology 35:821-826 doi:10.1111/jgh.14870

Page 8/17 
35. Warth A, Kloor M, Schirmacher P, Bläker H (2011) Genetics and epigenetics of small bowel adenocarcinoma: the interactions of $\mathrm{CIN}, \mathrm{MSI}$, and CIMP Modern pathology : an official journal of the United States and Canadian Academy of Pathology, Inc 24:564-570 doi:10.1038/modpathol.2010.223

36. Watari J et al. (2019) Molecular alterations and PD-L1 expression in non-ampullary duodenal adenocarcinoma: Associations among clinicopathological, immunophenotypic and molecular features Scientific reports 9:10526 doi:10.1038/s41598-01946167-y

37. Xue Y et al. (2017) Non-ampullary-duodenal carcinomas: clinicopathologic analysis of 47 cases and comparison with ampullary and pancreatic adenocarcinomas Modern pathology : an official journal of the United States and Canadian Academy of Pathology, Inc 30:255-266 doi:10.1038/modpathol.2016.174

38. Yang G, Zheng RY, Jin ZS (2019) Correlations between microsatellite instability and the biological behaviour of tumours Journal of cancer research and clinical oncology 145:2891-2899 doi:10.1007/s00432-019-03053-4

39. Yang G, Zheng RY, Tan Q, Dong CJ, Jin ZS (2020) Clinical characteristics and responses to chemotherapy and immune checkpoint inhibitor treatment for microsatellite instability gastric cancer American journal of cancer research 10:4123-4133

40. Yoshida M et al. (2019) Clinicopathological characteristics of non-ampullary duodenal tumors and their phenotypic classification Pathology international 69:398-406 doi:10.1111/pin.12829

41. Zaaimi Y, Aparicio T, Laurent-Puig P, Taieb J, Zaanan A (2016) Advanced small bowel adenocarcinoma: Molecular characteristics and therapeutic perspectives Clinics and research in hepatology and gastroenterology 40:154-160 doi:10.1016/j.clinre.2015.09.008

42. Zenali M et al. (2013) Clinicopathologic features and prognosis of duodenal adenocarcinoma and comparison with ampullary and pancreatic ductal adenocarcinoma Human pathology 44:2792-2798 doi:10.1016/j.humpath.2013.07.030

43. Zheng $Z$ et al. (2021) Nomograms predict survival of patients with small bowel adenocarcinoma: a SEER-based study International journal of clinical oncology 26:387-398 doi:10.1007/s10147-020-01813-8

44. Zhou QH et al. (2020) HHLA2 and PD-L1 co-expression predicts poor prognosis in patients with clear cell renal cell carcinoma Journal for immunotherapy of cancer 8 doi:10.1136/jitc-2019-000157

\section{Tables}

Table 1

Primer sequences

\begin{tabular}{|c|c|c|c|c|}
\hline Primers & Sequence & Product size (bp) & PCR cycle & AT \\
\hline NR-21 & $\begin{array}{l}\text { F: 5'-TAAATGTATGTCTCCCCTGG-3'-HEX } \\
\text { R: 5'-ATTCCTACTCCGCATTCACA-3' }\end{array}$ & 103 & 40 & $55^{\circ} \mathrm{C}$ \\
\hline NR-22 & $\begin{array}{l}\text { F: 5'-GAGGCTTGTCAAGGACATAA-3'-FAM } \\
\text { R: 5'-AATTCGGATGCCATCCAGTT-3' }\end{array}$ & 142 & 40 & $55^{\circ} \mathrm{C}$ \\
\hline NR-24 & $\begin{array}{l}\text { F: 5'-CCATTGCTGGAATTTTACCTC-3'-HEX } \\
\text { R: 5'-ATTGTGCCATTGCATTCCAA-3' }\end{array}$ & 132 & 40 & $55^{\circ} \mathrm{C}$ \\
\hline BAT-25 & $\begin{array}{l}\text { F: 5'-TCGCCTCCAAGAATGTAAGT-3'-TAMRA } \\
\text { R: 5'-TCTGCATTTTAACTATGGCTC-3' }\end{array}$ & 124 & 40 & $55^{\circ} \mathrm{C}$ \\
\hline BAT-26 & $\begin{array}{l}\text { F: 5'-TGACTACTTTTGACTTCAGCC-3'-FAM } \\
\text { R: 5'-AACCATTCAACATTTTTAACCC-3' }\end{array}$ & 120 & 40 & $55^{\circ} \mathrm{C}$ \\
\hline
\end{tabular}


Table 2

Clinicopathological and molecular characteristics

of invasive non-ampullary duodenal

adenocarcinoma. Abbreviation: M: male; F:

female; Oral-vater: oral side of the papilla of vater;

Anal-vater: anal side of the papilla of vater; PD-L1:

programmed cell death-ligand 1; MSS:

microsatellite stability; MSI: microsatellite instability.

\begin{tabular}{|c|c|c|}
\hline Clinical characteristics & $n=54$ & $\%$ \\
\hline Age, median (range) & $68(29-90)$ & \\
\hline \multicolumn{3}{|l|}{ Gender } \\
\hline$M$ & 36 & $66.7 \%$ \\
\hline $\mathrm{F}$ & 18 & $33.3 \%$ \\
\hline \multicolumn{3}{|l|}{ Tumor location } \\
\hline Oral-vater & 40 & $74.1 \%$ \\
\hline Anal-vater & 14 & $25.9 \%$ \\
\hline \multicolumn{3}{|l|}{ Histology } \\
\hline Differentiated & 42 & $77.8 \%$ \\
\hline Undifferentiated & 12 & $22.2 \%$ \\
\hline \multicolumn{3}{|l|}{ Mucin phenotype } \\
\hline Gastric & 33 & $61.1 \%$ \\
\hline Intestinal & 7 & $13.0 \%$ \\
\hline Mix & 6 & $11.1 \%$ \\
\hline Null & 8 & $14.8 \%$ \\
\hline \multicolumn{3}{|l|}{ PD-L1 (immune cells) } \\
\hline Positive & 32 & $59.3 \%$ \\
\hline Negative & 22 & $40.7 \%$ \\
\hline \multicolumn{3}{|l|}{ PD-L1 (tumor cells) } \\
\hline Positive & 24 & $44.4 \%$ \\
\hline Negative & 30 & $55.6 \%$ \\
\hline \multicolumn{3}{|l|}{ Tumor stage } \\
\hline 口 & 6 & $11.1 \%$ \\
\hline ૫ & 11 & $20.4 \%$ \\
\hline प & 16 & $29.6 \%$ \\
\hline ૫ & 21 & $38.9 \%$ \\
\hline \multicolumn{3}{|l|}{ MS status } \\
\hline MSS & 35 & $64.8 \%$ \\
\hline
\end{tabular}


Table 3

Relationship among clinicopathological characteristics, histological differentiation and PD-L1 expression.

\begin{tabular}{|c|c|c|c|c|c|c|c|c|c|}
\hline & \multicolumn{3}{|l|}{ Histology } & \multicolumn{3}{|c|}{$\begin{array}{l}\text { PD-L1 (immune } \\
\text { cells) }\end{array}$} & \multicolumn{3}{|c|}{$\begin{array}{l}\text { PD-L1 (tumour } \\
\text { cells) }\end{array}$} \\
\hline & Differentiated & Undifferentiated & $\mathrm{p}$ & Positive & Negative & $\mathrm{p}$ & Positive & Negative & $\mathrm{p}$ \\
\hline & $n=42$ & $n=12$ & & $n=32$ & $n=22$ & & $n=24$ & $n=30$ & \\
\hline $\begin{array}{l}\text { Age, median } \\
\text { (range) }\end{array}$ & $67(29-90)$ & $73(34-80)$ & 0.633 & $\begin{array}{l}68(34- \\
90)\end{array}$ & $\begin{array}{l}66.5 \\
(29-84)\end{array}$ & 0.391 & $\begin{array}{l}72(34- \\
90)\end{array}$ & $\begin{array}{l}66.5 \\
(29-84)\end{array}$ & 0.161 \\
\hline Gender & & & 0.506 & & & 1.000 & & & 1.000 \\
\hline M & 29 (69.0\%) & $7(58.3 \%)$ & & $\begin{array}{l}21 \\
(65.6 \%)\end{array}$ & $\begin{array}{l}15 \\
(68.2 \%)\end{array}$ & & $\begin{array}{l}16 \\
(66.7 \%)\end{array}$ & $\begin{array}{l}20 \\
(66.7 \%)\end{array}$ & \\
\hline $\mathrm{F}$ & $13(31.0 \%)$ & $5(41.7 \%)$ & & $\begin{array}{l}11 \\
(34.4)\end{array}$ & $\begin{array}{l}7 \\
(31.8 \%)\end{array}$ & & $\begin{array}{l}8 \\
(33.3 \%)\end{array}$ & $\begin{array}{l}10 \\
(33.3 \%)\end{array}$ & \\
\hline Tumor location & & & 0.152 & & & 0.282 & & & 0.165 \\
\hline Oral-vater & 29 (69.0\%) & $11(91.7 \%)$ & & $\begin{array}{l}22 \\
(68.8 \%)\end{array}$ & $\begin{array}{l}18 \\
(81.8 \%)\end{array}$ & & $\begin{array}{l}20 \\
(83.3 \%)\end{array}$ & $\begin{array}{l}20 \\
(66.7 \%)\end{array}$ & \\
\hline Anal-vater & $13(31.0 \%)$ & $1(8.3 \%)$ & & $\begin{array}{l}10 \\
(31.3 \%)\end{array}$ & $\begin{array}{l}4 \\
(18.2 \%)\end{array}$ & & $\begin{array}{l}4 \\
(16.7 \%)\end{array}$ & $\begin{array}{l}10 \\
(33.3 \%)\end{array}$ & \\
\hline Histology & & & & & & & & & 0.016 \\
\hline Differentiated & - & - & & $\begin{array}{l}22 \\
(68.8 \%)\end{array}$ & $\begin{array}{l}20 \\
(90.9 \%)\end{array}$ & 0.094 & $\begin{array}{l}15 \\
(62.5 \%)\end{array}$ & $\begin{array}{l}27 \\
(90 \%)\end{array}$ & \\
\hline Undifferentiated & - & - & & $\begin{array}{l}10 \\
(31.3 \%)\end{array}$ & $2(9.1 \%)$ & & $\stackrel{9}{(37.5 \%)}$ & $3(10 \%)$ & \\
\hline $\begin{array}{l}\text { Mucin } \\
\text { phenotype }\end{array}$ & & & 0.037 & & & 0.075 & & & 0.265 \\
\hline Gastric & 28 (66.7\%) & $5(41.7 \%)$ & & $\begin{array}{l}17 \\
(53.1 \%)\end{array}$ & $\begin{array}{l}16 \\
(72.7 \%)\end{array}$ & & $\begin{array}{l}16 \\
(66.7 \%)\end{array}$ & $\begin{array}{l}17 \\
(56.7 \%)\end{array}$ & \\
\hline Intestinal & $6(14.3 \%)$ & $1(8.3 \%)$ & & $\begin{array}{l}6 \\
(18.8 \%)\end{array}$ & $1(4.5 \%)$ & & $\begin{array}{l}2 \\
(8.3 \%)\end{array}$ & $\begin{array}{l}5 \\
(16.7 \%)\end{array}$ & \\
\hline Mix & $5(11.9 \%)$ & $1(8.3 \%)$ & & $\begin{array}{l}2 \\
(6.3 \%)\end{array}$ & $\begin{array}{l}4 \\
(18.2 \%)\end{array}$ & & $\begin{array}{l}1 \\
(4.2 \%)\end{array}$ & $\begin{array}{l}5 \\
(16.7 \%)\end{array}$ & \\
\hline Null & $3(7.1 \%)$ & $5(41.7 \%)$ & & $\begin{array}{l}7 \\
(21.9 \%)\end{array}$ & $1(4.5 \%)$ & & $\begin{array}{l}5 \\
(20.8 \%)\end{array}$ & $\begin{array}{l}3 \\
(10.0 \%)\end{array}$ & \\
\hline PD-L1 (immune c & & & 0.094 & & & & & & \\
\hline Positive & $22(52.4 \%)$ & $10(83.3 \%)$ & & - & - & & - & - & \\
\hline Negative & $20(47.6 \%)$ & $2(16.7 \%)$ & & - & - & & - & - & \\
\hline $\begin{array}{l}\text { PD-L1 (tumour } \\
\text { cells) }\end{array}$ & & & 0.016 & & & & & & \\
\hline Positive & $15(35.7 \%)$ & $9(75.0 \%)$ & & - & - & & - & - & \\
\hline Negative & 27 (64.3\%) & $3(25.0 \%)$ & & - & - & & - & - & \\
\hline Tumor stage & & & 0.023 & & & 0.054 & & & 1.000 \\
\hline ૫ & $5(11.9 \%)$ & $1(8.3 \%)$ & & $\begin{array}{l}1 \\
(3.1 \%)\end{array}$ & $\begin{array}{l}5 \\
(22.7 \%)\end{array}$ & & $\begin{array}{l}3 \\
(12.5 \%)\end{array}$ & $\begin{array}{l}3 \\
(10.0 \%)\end{array}$ & \\
\hline
\end{tabular}




\begin{tabular}{|c|c|c|c|c|c|c|c|c|c|}
\hline \multirow[b]{2}{*}{ 口 } & \multicolumn{3}{|l|}{ Histology } & \multicolumn{3}{|c|}{$\begin{array}{l}\text { PD-L1 (immune } \\
\text { cells) }\end{array}$} & \multicolumn{3}{|c|}{$\begin{array}{l}\text { PD-L1 (tumour } \\
\text { cells) }\end{array}$} \\
\hline & $11(26.2 \%)$ & $0(0.0 \%)$ & & $\begin{array}{l}9 \\
(28.1 \%)\end{array}$ & $2(9.1 \%)$ & & $\begin{array}{l}5 \\
(20.8 \%)\end{array}$ & $\begin{array}{l}6 \\
(20.0 \%)\end{array}$ & \\
\hline ૫ & $14(33.3 \%)$ & $2(16.7 \%)$ & & $\begin{array}{l}11 \\
(34.4)\end{array}$ & $\begin{array}{l}5 \\
(22.7 \%)\end{array}$ & & $\begin{array}{l}7 \\
(29.2 \%)\end{array}$ & $\begin{array}{l}9 \\
(30.0 \%)\end{array}$ & \\
\hline प & $12(28.6 \%)$ & $9(75.0 \%)$ & & $\begin{array}{l}11 \\
(34.4)\end{array}$ & $\begin{array}{l}10 \\
(45.5 \%)\end{array}$ & & $\begin{array}{l}9 \\
(37.5 \%)\end{array}$ & $\begin{array}{l}12 \\
(40.0 \%)\end{array}$ & \\
\hline MS status & & & 0.178 & & & 0.88 & & & 0.75 \\
\hline MSS & 25 (59.5\%) & 10 (83.3\%) & & $\begin{array}{l}21 \\
(65.6 \%)\end{array}$ & $\begin{array}{l}14 \\
(63.6 \%)\end{array}$ & & $\begin{array}{l}15 \\
(62.5 \%)\end{array}$ & $\begin{array}{l}20 \\
(66.7 \%)\end{array}$ & \\
\hline $\mathrm{MSI}$ & $17(40.5 \%)$ & $2(16.7 \%)$ & & $\begin{array}{l}11 \\
(34.4)\end{array}$ & $\begin{array}{l}8 \\
(36.4 \%)\end{array}$ & & $\begin{array}{l}9 \\
(37.5 \%)\end{array}$ & $\begin{array}{l}10 \\
(33.3 \%)\end{array}$ & \\
\hline
\end{tabular}


Table 4

Relationship between clinicopathological characteristics and microsatellite status.

\begin{tabular}{|c|c|c|c|}
\hline & \multicolumn{3}{|c|}{ Microsatellite status } \\
\hline & MSS & MSI & $\mathrm{p}$ \\
\hline & $\mathrm{n}=35$ & $\mathrm{n}=19$ & \\
\hline Age, median (range) & $68(29-90)$ & $67(51-84)$ & 0.346 \\
\hline Gender & & & 0.158 \\
\hline M & $21(60.0 \%)$ & $15(78.9 \%)$ & \\
\hline $\mathrm{F}$ & $14(40.0 \%)$ & $4(21.1 \%)$ & \\
\hline Tumor location & & & 0.058 \\
\hline Oral-vater & $29(82.9 \%)$ & $11(57.9 \%)$ & \\
\hline Anal-vater & $6(17.1 \%)$ & $8(42.1 \%)$ & \\
\hline Histology & & & 0.178 \\
\hline Differentiated & $25(71.4 \%)$ & $17(89.5 \%)$ & \\
\hline Undifferentiated & $10(28.6 \%)$ & $2(10.5 \%)$ & \\
\hline Mucin phenotype & & & 0.507 \\
\hline Gastric & $20(57.1 \%)$ & $13(68.4 \%)$ & \\
\hline Intestinal & $6(17.1 \%)$ & $1(5.3 \%)$ & \\
\hline Mix & $3(8.6 \%)$ & $3(15.8 \%)$ & \\
\hline Null & $6(17.1 \%)$ & $2(10.5 \%)$ & \\
\hline PD-L1 (immune cells) & & & 0.88 \\
\hline Positive & $21(60.0 \%)$ & $11(57.9 \%)$ & \\
\hline Negative & $14(40.0 \%)$ & $8(42.1 \%)$ & \\
\hline PD-L1 (tumor cells) & & & 0.75 \\
\hline Positive & $15(42.9 \%)$ & $9(47.4 \%)$ & \\
\hline Negative & $20(57.1 \%)$ & $10(52.6 \%)$ & \\
\hline Tumor stage & & & 0.251 \\
\hline$\square$ & $3(8.6 \%)$ & $3(15.8 \%)$ & \\
\hline ૫ & $6(17.1 \%)$ & $5(26.3 \%)$ & \\
\hline ૫ & $9(25.7 \%)$ & $7(36.8 \%)$ & \\
\hline प & $17(48.6 \%)$ & $4(21.1 \%)$ & \\
\hline
\end{tabular}


Table 5

Univariate and multivariate analysis of factors related to patients' overall survival.

\begin{tabular}{|c|c|c|c|c|c|c|}
\hline & \multicolumn{3}{|c|}{ Univariate analysis } & \multicolumn{3}{|c|}{ Multivariate analysis } \\
\hline & $\mathrm{HR}$ & $95 \% \mathrm{Cl}$ & $\mathrm{P}$ & $\mathrm{HR}$ & $95 \% \mathrm{Cl}$ & $\mathrm{P}$ \\
\hline MS status (MSI vs MSS) & 0.377 & $\begin{array}{l}0.169- \\
0.839\end{array}$ & 0.017 & 0.282 & $\begin{array}{l}0.106- \\
0.751\end{array}$ & 0.011 \\
\hline PD-L1 expression in immune cells (positive vs negative) & 1.471 & $\begin{array}{l}0.703- \\
3.078\end{array}$ & 0.305 & 1.634 & $\begin{array}{l}0.639- \\
4.179\end{array}$ & 0.306 \\
\hline PD-L1 expression in tumour cells (positive vs negative) & 1.275 & $\begin{array}{l}0.627- \\
2.593\end{array}$ & 0.502 & 1.546 & $\begin{array}{l}0.619- \\
3.861\end{array}$ & 0.35 \\
\hline $\begin{array}{l}\text { Histological differentiation (undifferentiated type vs } \\
\text { differentiated type) }\end{array}$ & 1.778 & $\begin{array}{l}0.754- \\
4.192\end{array}$ & 0.188 & 0.527 & $\begin{array}{l}0.171- \\
1.626\end{array}$ & 0.265 \\
\hline Tumor stage $(\llbracket$ and $\nabla$ vs $\square$ and $\nabla)$ & 8.612 & $\begin{array}{l}2.553- \\
29.058\end{array}$ & 0.001 & 8.81 & $\begin{array}{l}2.545- \\
30.500\end{array}$ & 0.001 \\
\hline Tumour location (anal-vater vs oral-vater) & 0.852 & $0.39-1.860$ & 0.687 & 1.295 & $\begin{array}{l}0.471- \\
3.559\end{array}$ & 0.617 \\
\hline
\end{tabular}

\section{Figures}
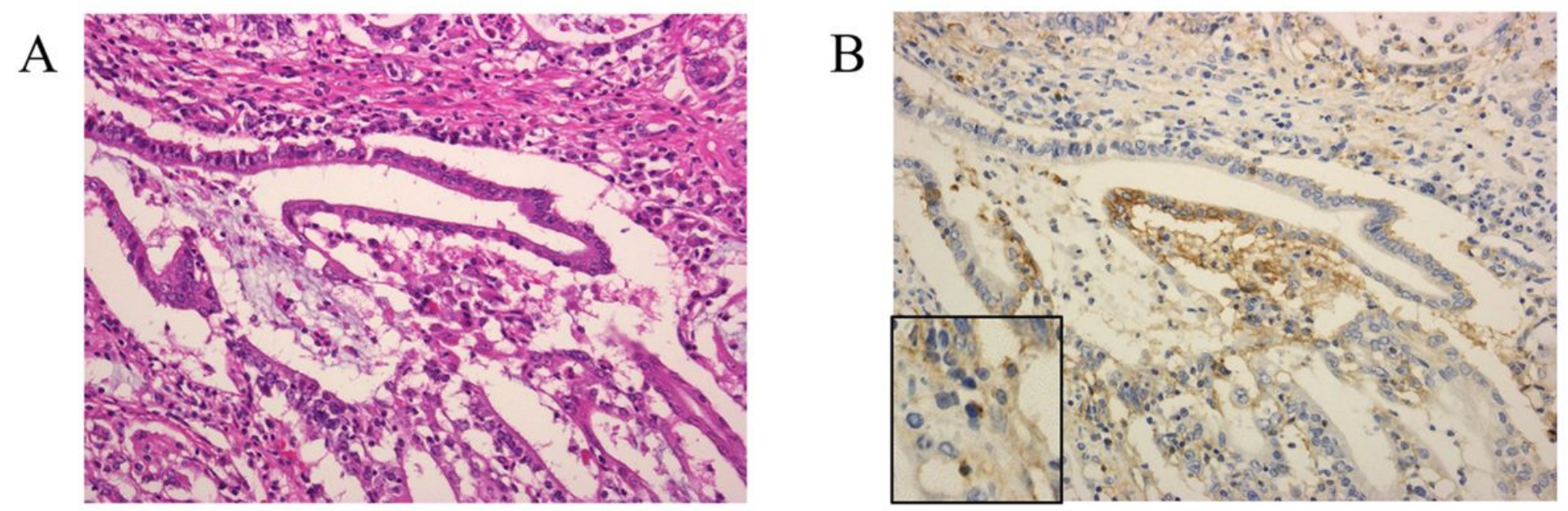

\section{Figure 1}

Images of hematoxylin and eosin (a) and PD-L1-positive staining (b) in patients with INADA. b: PD-L1 positive expression on tumor and immune cells. Insert: positive expression of PD-L1 on immune cells 


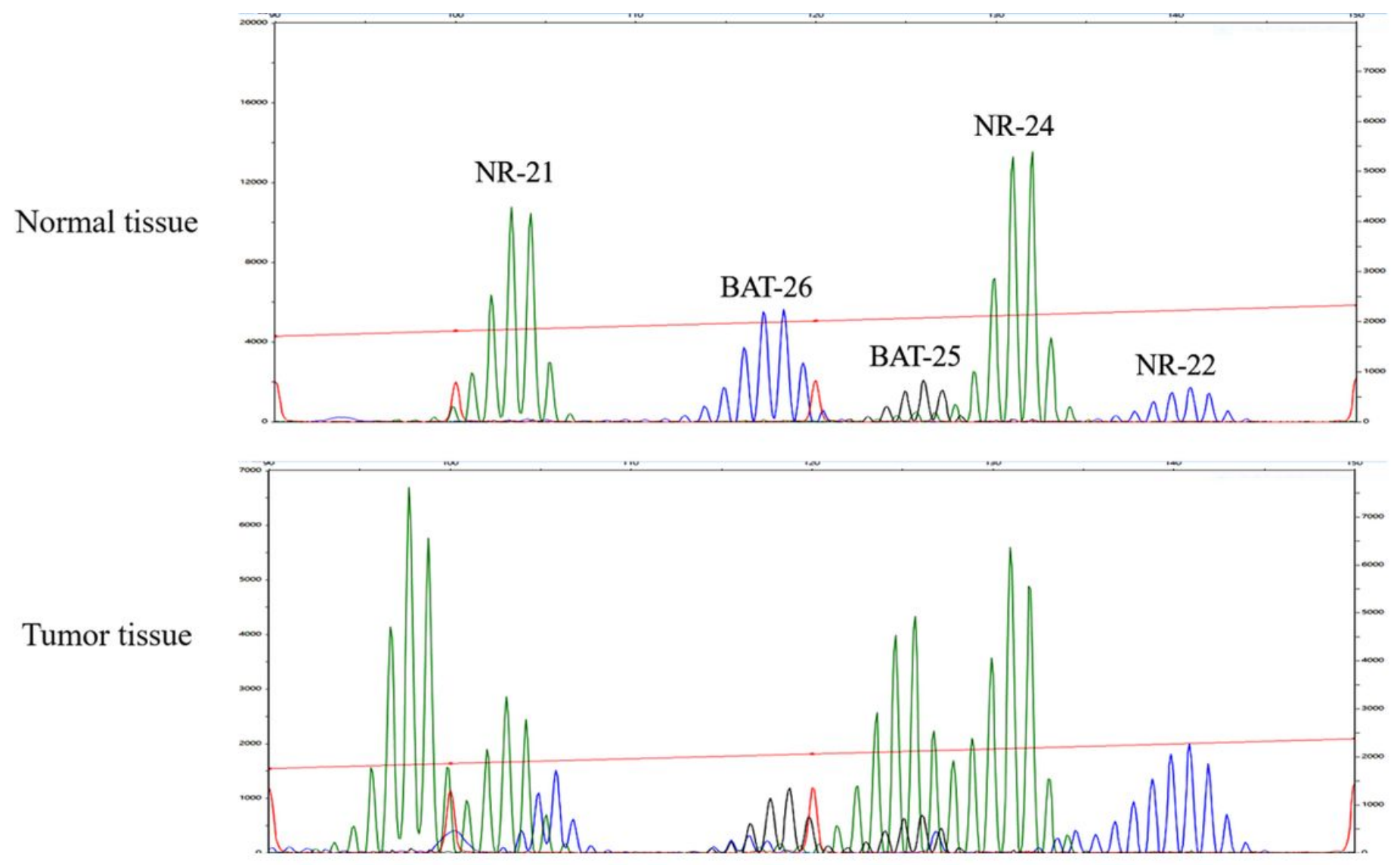

Figure 2

A representative patient with the MSI phenotype. Compared to normal tissue, obvious length changes in microsatellite markers NR21, NR-24, BAT-25 and BAT-26 were observed
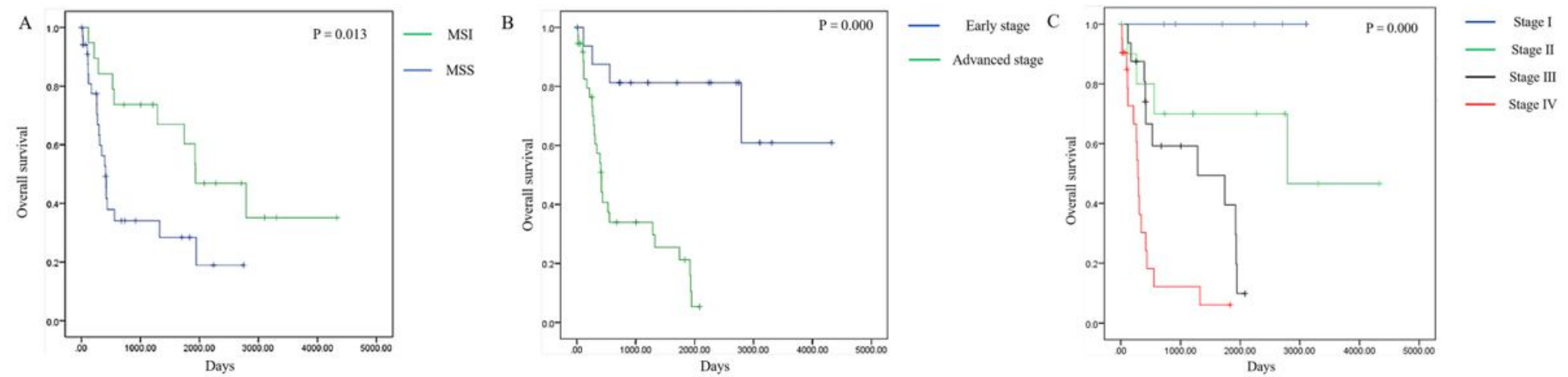

Figure 3

Kaplan-Meier survival curve of invasive nonampullary duodenal adenocarcinoma based on microsatellite status (a) and tumor stage ( $b$ and $c)$. a: INADA with MSI was associated with better OS; $b$ : INADA with early stage was associated with better OS; $c$ : The survival of patients gradually worsened with increasing tumor stage 

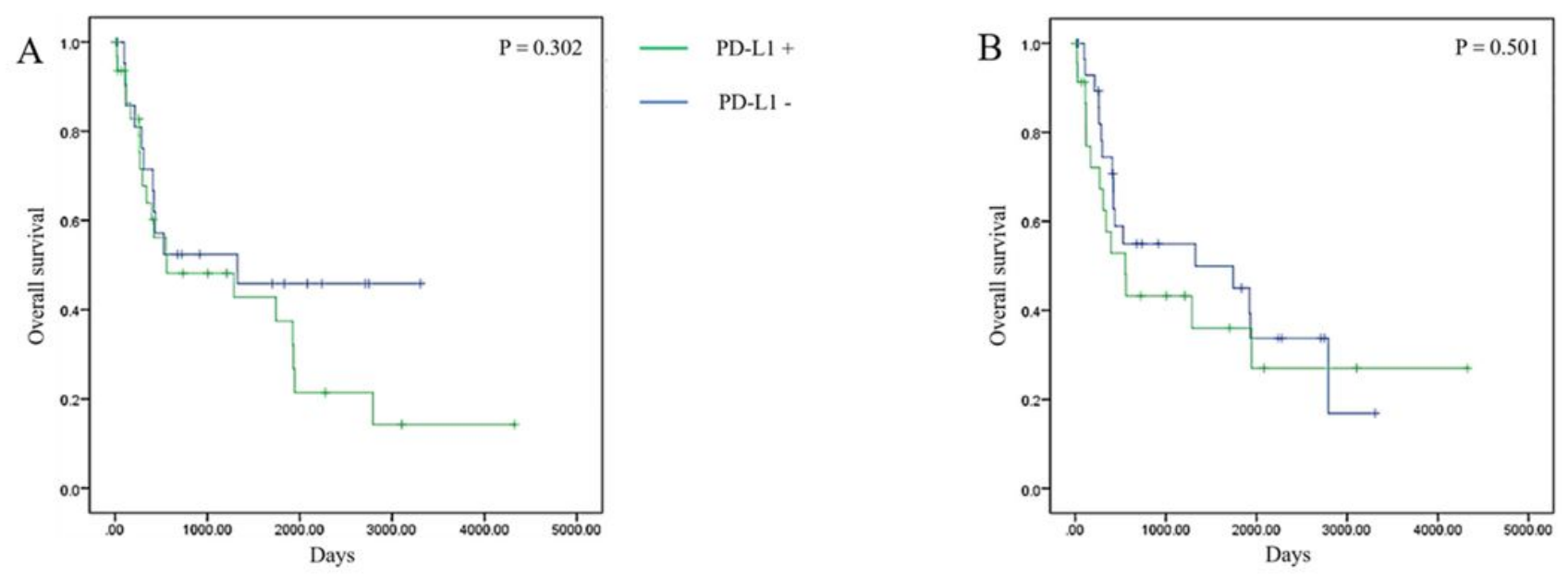

- PD-L1 +
$-\quad$ PD-L1 -
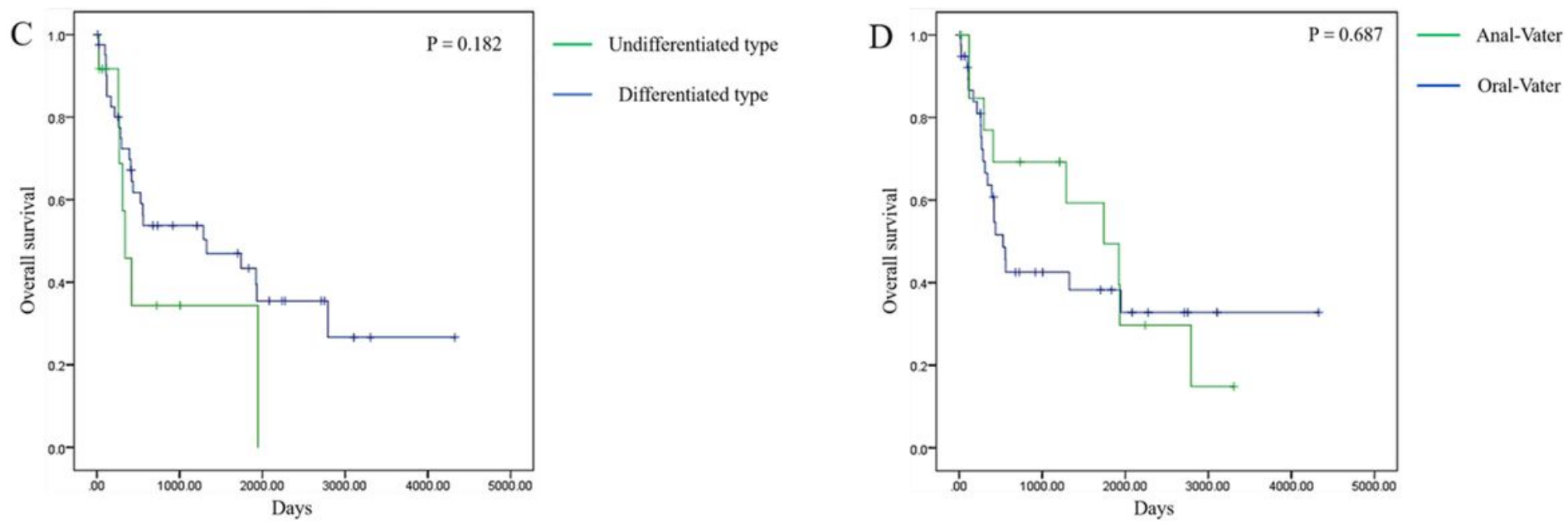

Figure 4

Kaplan-Meier survival curve of invasive nonampullary duodenal adenocarcinoma based on PD-L1 expression on immune cells (a), PD-L1 expression on tumor cells (b), tumor type (c) and tumor location (d) 